\title{
ИОННО-ЛУЧЕВОЕ ФОРМИРОВАНИЕ И ТРЕКОВАЯ МОДИФИКАЦИЯ НАНОКЛАСТЕРОВ InAs В КРЕМНИИ И ДИОКСИДЕ КРЕМНИЯ
}

\author{
(C) 2016 г. Ф. Ф. Комаров ${ }^{1}$, О. В. Мильчанин ${ }^{1}$, В. А. Скуратов ${ }^{2}$, М. А. Моховиков ${ }^{1}$, \\ A. Janse van Vuuren ${ }^{3}$, J. N. Neethling ${ }^{3}$, E. Wendler ${ }^{4}$, Л. А. Власукова ${ }^{5}$, \\ И. Н. Пархоменко ${ }^{5}$, В. Н. Ювченко \\ E-mail:komarovf@bsu.by
}

\begin{abstract}
Проведены исследования имплантационного формирования нанокластеров InAs в кремнии и диоксиде кремния и их перестройки при облучении ионами Хе с энергией 167 МэВ флюенсом $3 \cdot 10^{14} \mathrm{~cm}^{-2}$. Постимплантационный отжиг и облучение высокоэнергетичными ионами вызывают изменения размеров и формы нанокластеров, а также структурные превращения в них. Обнаружено упорядочение нанокластеров и их вытягивание вдоль траектории ионов Хе в матрице $\mathrm{SiO}_{2}$.
\end{abstract}

DOI: $10.7868 / \mathrm{S} 0367676516020149$

\section{ВВЕДЕНИЕ}

В последние годы большое внимание уделяется проблемам создания комбинированных систем микроэлектроники и фотоники на кремнии, а также замены электронной межэлементной коммутации в кремниевых высокоинтегрированных системах на оптическую. Кремний - непрямозонный полупроводник в связи с чем не является удобным материалом для этих целей. В ряде публикаций как авторов данной работы [1-3], так и других групп [4] исследуется формирование нанокристаллов прямозонных полупроводников $\mathrm{A}^{3} \mathrm{~B}^{5}$, включая узкозонные (InAs, InSb, GaSb), путем пересыщения кремния примесями III и V группы Периодической системы с последующими термообработками (длительными равновесными или быстрыми). Для систем “нанокластеры $\mathrm{A}^{3} \mathrm{~B}^{5}$ в кремнии” наблюдается интенсивная фотолюминесценция в ближнем ИК-диапазоне (0.75-1.1 эВ). Важные задачи: выяснение механизмов этой люминесценции и поиск путей синтеза нанокристаллов с узким распределением по размерам. Облучение ионами средних и высоких энергий позволяет селективно управлять размерами сформированных нанокластеров [5].

В данной работе нанокластеры InAs синтезировались в $\mathrm{Si}$ и $\mathrm{SiO}_{2}$ высокодозной ионной имплантацией с последующей термообработкой и/или облучением высокоэнергетическими ионами ксенона.

\footnotetext{
${ }^{1}$ Институт прикладных физических проблем имени А.Н. Севченко БГУ, Минск, Беларусь.

2 Объединенный институт ядерных исследований, Дубна, Россия.

${ }^{3}$ Centre for HRTEM, Nelson Mandela Metropolitan University,

Port Elizabeth, South Africa.

${ }^{4}$ Friedrich-Schiller-Universitдt, Jena, Germany.

${ }^{5}$ Белгосуниверситет, Минск, Беларусь.
}

\section{МЕТОДИКА}

Пластины $n$-Si (100) с термическим $\mathrm{SiO}_{2}$ толщиной 40 или 600 нм облучались вначале ионами $\mathrm{As}^{+}\left(170 \mathrm{\kappa эB}, 3.2 \cdot 10^{16} \mathrm{~cm}^{-2}\right)$, а затем ионами $\mathrm{In}^{+}$ $\left(250\right.$ кэВ, $\left.2.8 \cdot 10^{16} \mathrm{~cm}^{-2}\right)$. Облучение системы $\mathrm{SiO}_{2}$ (40 нм)/Si проводилось при $T=550^{\circ} \mathrm{C}$, а системы $\mathrm{SiO}_{2}(0.6$ нм)/Si при $T=300 \mathrm{~K}$. Потом часть образцов отжигалась при $900^{\circ} \mathrm{C}$ в среде аргона для преципитации нанокластеров InAs: 45 мин для системы $\mathrm{SiO}_{2}(40 \mathrm{Hм}) / \mathrm{Si}$ и 30 мин для системы $\mathrm{SiO}_{2}(600 \mathrm{Hм}) / \mathrm{Si}$. После этого часть отожжённых и часть не прошедших термообработку образцов облучалась высокоэнергетичными ионами $\mathrm{Xe}^{+}$ $\left(167 \mathrm{MэB}, 3 \cdot 10^{14} \mathrm{~cm}^{-2}\right)$ при комнатной температуpe. Для анализа структурных и оптических свойств исследуемых систем использовали просвечивающую электронную микроскопию (ТЕМ, ХTЕМ) и комбинационное рассеяние света (KPC).

\section{РЕЗУЛЬТАТЫ И ОБСУЖДЕНИЕ}

Для исследования структурных и фазовых изменений в системе $\mathrm{SiO}_{2}$ при облучении быстрыми ионами Хе в рамках модели термического пика [6] были выполнены расчеты термических полей в $\mathrm{SiO}_{2}$, оценены радиус и время жизни расплавленной области при прохождении ионов Хе. Как следует из расчетов, радиус расплавленной области составляет 6 нм, а время ее жизни 23.8 пс.

Для обсуждения результатов воздействия быстрых ионов Хе на нанокластеры InAs в $\mathrm{SiO}_{2}$ важно оценить также максимальный размер нанокластеров InAs, которые будут плавиться при

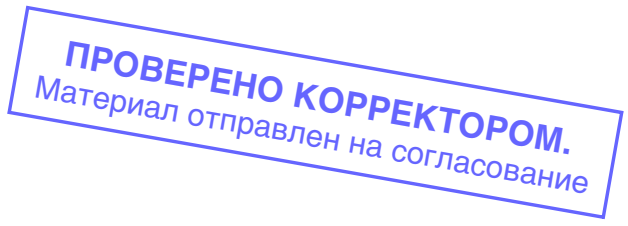




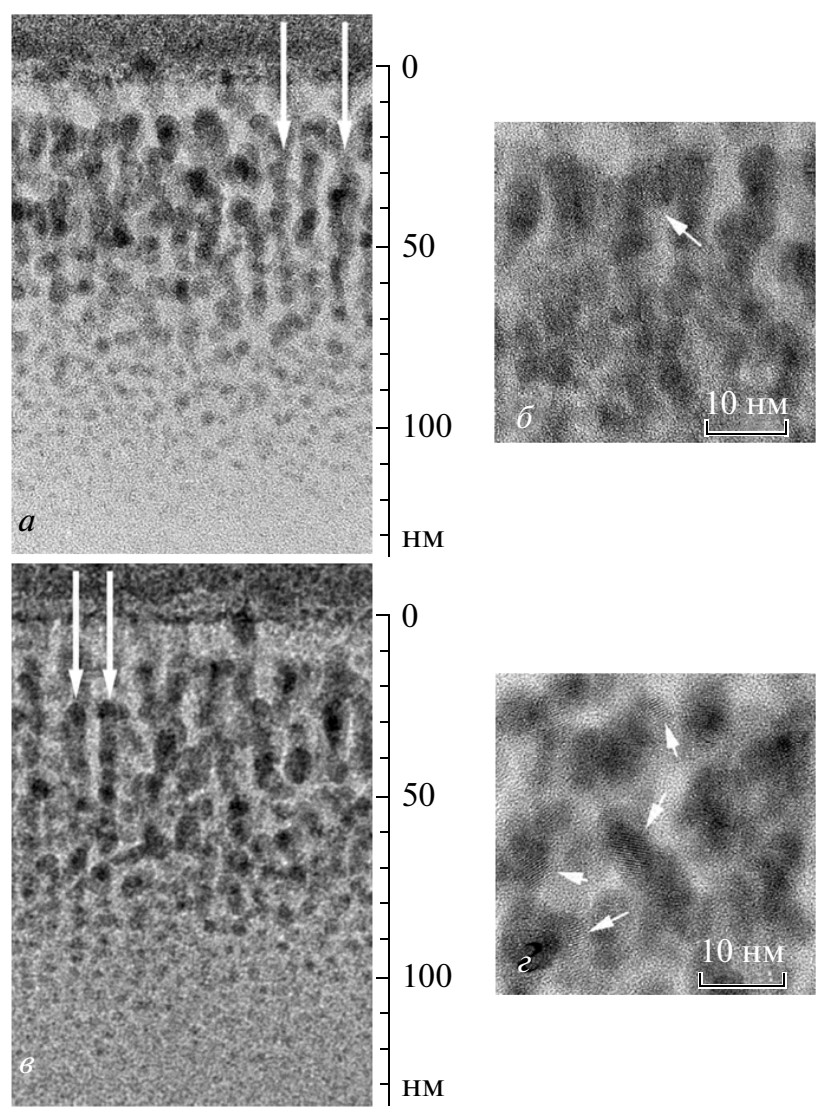

Рис. 1. ПЭМ-микрофотографии в режимах поперечного сечения и высокого разрешения структур $\mathrm{SiO}_{2}(600$ нм)/Si после имплантации ионов As $\left(170 \mathrm{kэB}, 3.2 \cdot 10^{16}\right)+\operatorname{In}\left(250 \mathrm{kэB}, 2.8 \cdot 10^{16}\right)$ при температуре $550{ }^{\circ} \mathrm{C}(a)$ и последующей термообработки $900^{\circ} \mathrm{C}, 45$ мин (б), а также после облучения ионами $\mathrm{Xe}(b, 2)$.

облучении 167 МэВ-ными ионами Хе. В литературе используется выражение [7]

$$
R_{N P}^{\max }=\sqrt{\frac{3(d E / d x)_{e, N P}}{2 \pi H_{N P}^{m} \rho_{N P}}},
$$

где $(d E / d x)_{e, N P}-$ удельные потери энергии иона на электронные возбуждения в наночастице, $\rho_{N P}-$ плотность материала в этой частице, $H_{N P}^{m}$ - теплота плавления. Мы считаем, что более правильно учитывать еще и энергию, идущую на нагрев наночастицы до температуры плавления:

$$
R_{N P}^{\max }=\sqrt{\frac{3(d E / d x)_{e, N P}}{2 \pi\left(H_{N P}^{m} \rho_{N P}+Q\right)}},
$$

где $Q($ InAs $)=\rho_{N P} C\left(T_{m}-T_{i r r}\right)=1820$ Дж $\cdot \mathrm{cm}^{-3}, C-$ удельная теплоемкость, $T_{m}$ - температура плавления, $T_{i r r}$ - температура образца при облучении.

С учетом характеристик материала нанокластеров InAs $\left(\rho_{N P}=5.67 \Gamma \cdot \mathrm{cm}^{-3}, H_{N P}^{m}=503\right.$ Дж $\left.\cdot \Gamma^{-1}\right)$ и $(d E / d x)_{e, N P}=19.2$ кэВ $\cdot \mathrm{HM}^{-1}($ SRIM 2015) полу- чим для $R_{N P}^{\max }=22.8$ нм по формуле (1) и 17.8 нм из выражения (2).

Как известно из результатов экспериментальных исследований, облучение монокристаллического кремния любыми быстрыми индивидуальными (не кластерными) ионами не сопровождается формированием регистрируемых трековых областей [8]. Считается, что это вызвано быстрой эпитаксиальной кристаллизацией расплавленных областей вокруг траектории ионов в кремнии.

На рис. 1 представлены ПЭМ изображения поперечного сечения слоя диоксида кремния, облученного ионами $\mathrm{Xe}^{+}$сразу после имплантации мышьяка и индия (рис. 1a), а также после имплантации и термообработки (рис. 1в). Видно, что структура диоксида кремния с нанокластерами в обоих случаях сопоставима. Кластеры наблюдаются в области глубин от 0 до 120 нм. При этом можно выделить два слоя: первый - на глубине от 0 до 70 нм, где регистрируются более крупные кластеры (5-8 нм); второй - на глубине от 70 до 120 нм, содержащий мелкие кластеры (2-4 нм). В обоих образцах приповерхностный слой толщиной 10-15 нм практически не содержит кластеров. Форма преципитатов округлая, но часть их в слое от 0 до 70 нм имеет вытянутую (овальную) форму вдоль направления, перпендикулярного поверхности образцов. Форма мелких кластеров в более глубоком слое (70-120 нм) практически круглая. Облучение ионами Хе приводит к формированию областей перекрытия (объединения) кластеров в протяженные зоны длиной до 5060 нм (указаны стрелками на рис. 1).

Кроме того, облучение ионами Хе приводит к дроблению крупных кластеров InAs и формированию мелких размерами 6-8 нм. При флюенсе ксенона $3 \cdot 10^{14} \mathrm{~cm}^{-2}$ с учетом размера трековых (расплавленных) областей $\mathrm{SiO}_{2}$, приведенных выше, наблюдается 339-кратное перекрытие треков, поэтому финальное распределение нанокластеров по размерам слабо зависит от их распределения по размерам до облучения. На рис. 16 , г показаны более детальные изображения синтезированных в диоксиде кремния кластеров InAs, полученные с помощью электронной микроскопии высокого разрешения. Установлено, что для образца облученного ионами Хе сразу после имплантации ионов мышьяка и индия регистрируются преимущественно аморфные выделения.

Лишь малая их часть (несколько процентов) в приповерхностной области имеет кристаллическую природу. На рис. 16 стрелкой показан один из них. Рассчитанные по ПЭМ-изображениям межплоскостные расстояния в таких преципитатах составляют $0.348 \pm 0.005$ нм. Это хорошо согласуется с табличными данными для плоскостей семейства $\{111\}$ кристаллического InAs (0.3489 нм). Кристаллические преципитаты регистрируются и 
для облученного ионами Хе образца диоксида кремния после имплантаций $\left(\mathrm{As}^{+}+\mathrm{In}^{+}\right)$и термообработки (указано стрелками на рис. 12). Но в этом случае их количество гораздо больше - оценочно свыше $60 \%$ от всех кластеров. Из рис. 1 также видно, что кластеры (как кристаллические, так и аморфные) преимущественно вытянуты перпендикулярно поверхности (направление сверху вниз). Наблюдаются также области объединения кластеров вдоль этого направления.

На рис. 2 представлены характерные светлопольные ПЭМ-изображения поперечного сечения структур $\mathrm{SiO}_{2}(40$ нм)/Si, облученных ксеноном после "горячей" имплантации ионов мышьяка и индия, а также после имплантации и отжига. В облученном ионами Хе кристаллическом кремнии после “кластерообразующей” имплантации толщина дефектного слоя 240 нм (рис. 2a). Это гораздо больше, чем для диоксида кремния (120 нм); следовательно, повышенная температура имплантации $\left(550^{\circ} \mathrm{C}\right)$ приводит к большей диффузии атомов индия и мышьяка в монокристаллическом кремнии уже в процессе имплантации.

Этот разупорядоченный слой остается кристаллическим, но содержит дефектные кластеры и мелкие микродвойники. Зарегистрировано и образование кристаллических преципитатов InAs, о чем свидетельствуют муаровые полосы на них (показаны стрелками на рис. 2a). Эти преципитаты размером до 20 нм локализованы на глубине до 100 нм. Облучение быстрыми ионами приводит к заметному восстановлению кристаллической структуры кремния как в образцах сразу после имплантаций ионов мышьяка и индия, так и после термообработки имплантированных образцов (рис. 2б). Вторичные дефекты структуры, преимущественно мелкие дислокации, регистрируются на глубине 240 нм. Весь слой кремния имеет кристаллическую структуру с внедренными кристаллами InAs, значительная часть которых характеризуется размером до 50 нм (стрелки № 1 на рис. 2б). Но в приповерхностном слое до глубин 200 нм обнаружены и мелкие (2-5 нм) кристаллики InAs (показано стрелками № 2 на рис. 26).

Для идентификации преципитатов в $\mathrm{Si}$ и $\mathrm{SiO}_{2}$ после термообработок и облучения ионами Хе использован метод КРС. Известно, что полосы КРС с максимумами при 217.3 и 238.6 см$^{-1}$ соответствуют поперечным (TO) и продольным (LO) оптическим фононам кристаллической фазы InAs [9]. Положение максимумов может изменяться в зависимости от размеров нанокристаллов и наличия напряжений.

На рис. 3 представлены спектры КРС образцов $\mathrm{SiO}_{2}\left(0.6\right.$ мкм)/Si и $\mathrm{SiO}_{2}(40$ нм$) / \mathrm{Si}$, имплантированных ионами In и As до и после термообработки. Как видно из рисунка, в спектре КРС для исход- $a$
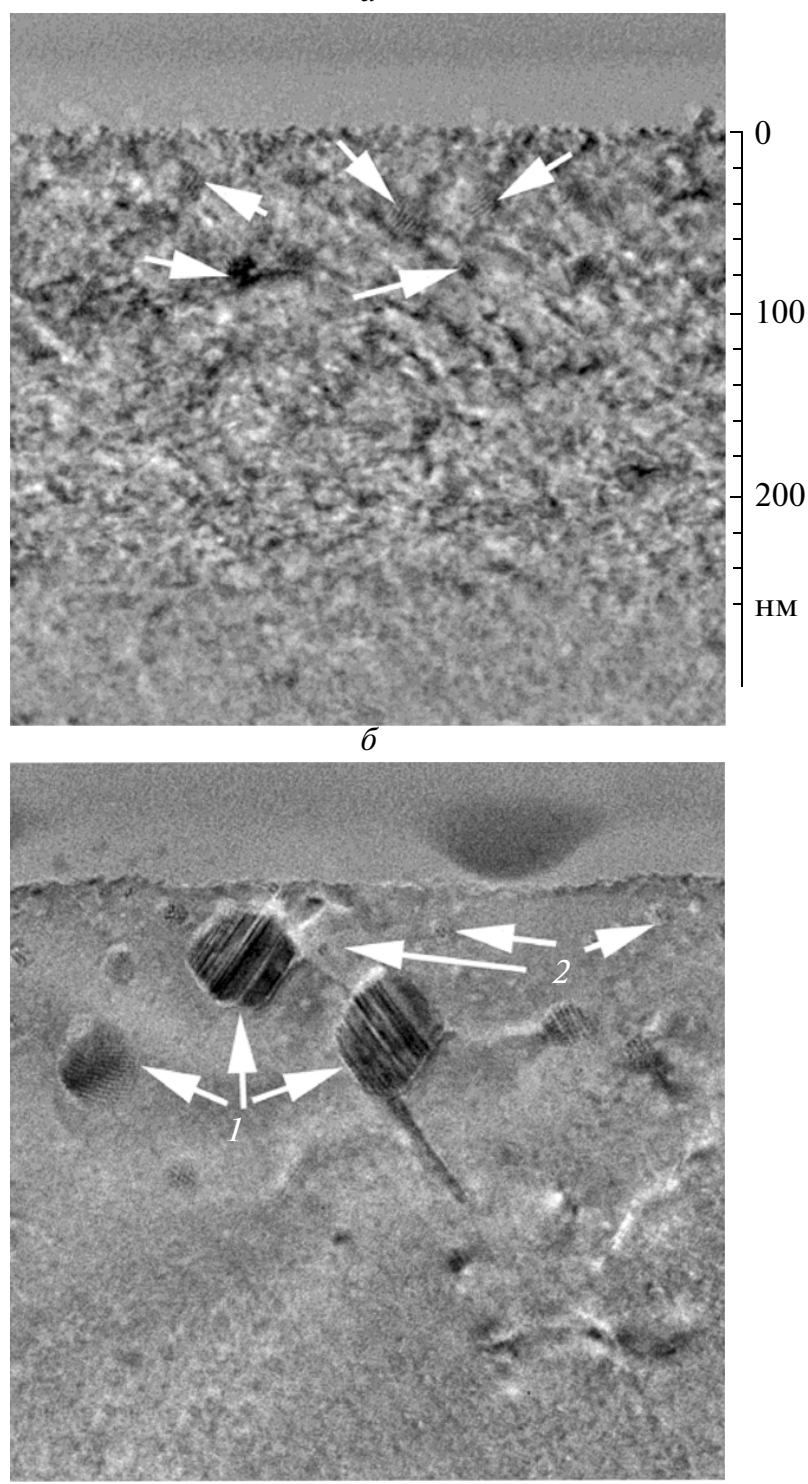

Рис. 2. ПЭМ-микрофотографии поперечного сечения структур $\mathrm{SiO}_{2}(40 \mathrm{HM}) / \mathrm{Si}$ после имплантации ионов As $\left(170\right.$ кэВ, $\left.3.2 \cdot 10^{16}\right)+\operatorname{In}\left(250\right.$ кэB, $\left.2.8 \cdot 10^{16}\right)$ при температуре $550^{\circ} \mathrm{C}(a)$ и термообработки $900^{\circ} \mathrm{C}, 45$ мин (б), а также после облучения ионами $\mathrm{Xe}(a, \sigma)$.

ной имплантированной пленки $\mathrm{SiO}_{2}$ регистрируется слабая полоса в области оптических фононов кристаллического InAs. По данным ПЭМ, нанокристаллы InAs сформировались как в исходном имплантированном образце $\mathrm{SiO}_{2}(0.6$ мкм $) / \mathrm{Si}$, так и в образце $\mathrm{SiO}_{2}(40$ нм)/Si. Отсутствие сигнала KРС от кристаллической фазы InAs для исходного имплантированного образца $\mathrm{SiO}_{2}(40 \mathrm{Hм}) / \mathrm{Si}$, вероятно, связано с меньшей глубиной проникновения возбуждающего излучения (473 нм), чем в случае образца $\mathrm{SiO}_{2}(0.6$ мкм $) / \mathrm{Si}$. 

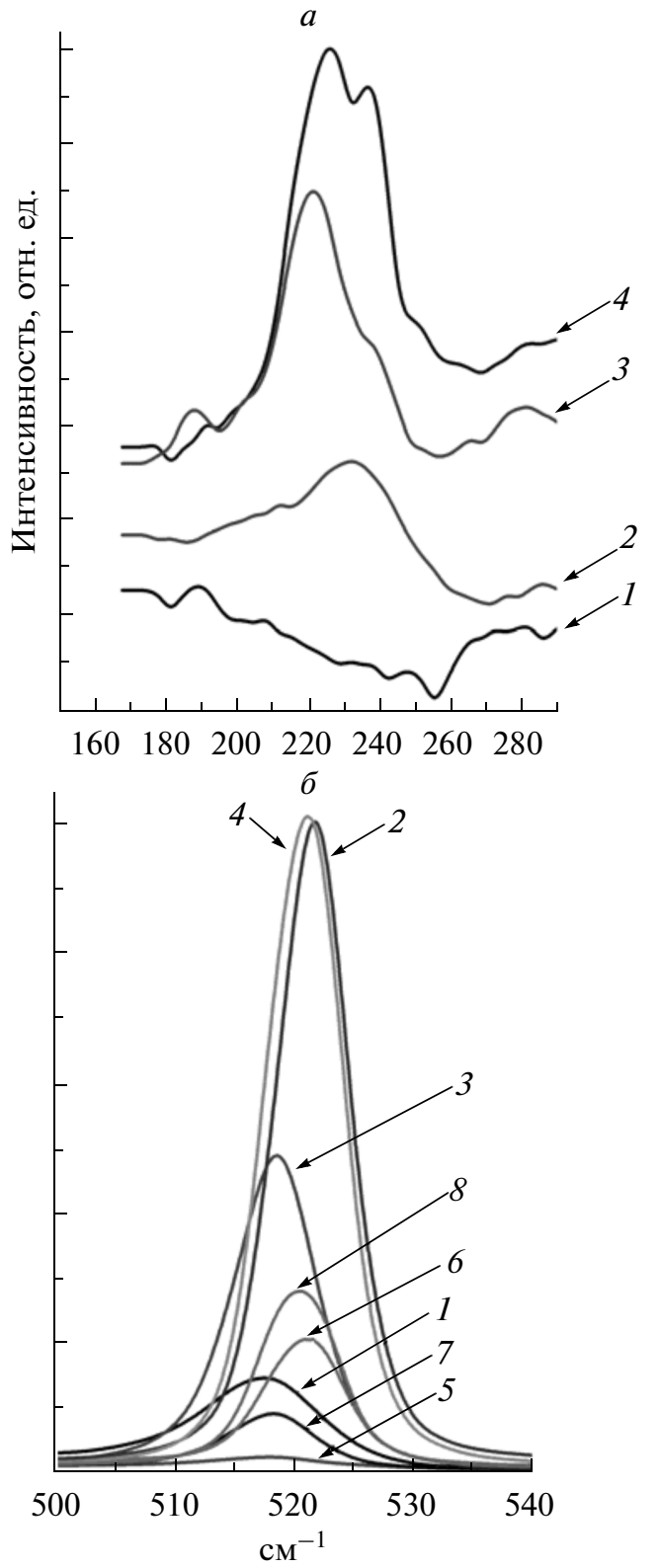

Рис. 3. Спектры КРС образцов $\mathrm{SiO}_{2}(40$ нм)/Si (кривые 1, 3, 5, 7) и $\mathrm{SiO}_{2}(600$ нм)/Si (кривые 2, 4, 6, 8), имплантированные ионами As и In в области оптических фононов кристаллического InAs $(a)$ и кристаллического $\mathrm{Si}($ (): 1,2 - исходные, 3 - после отжига $900^{\circ} \mathrm{C}, 45$ мин; 4 - после отжига $900^{\circ} \mathrm{C}, 30$ мин, 5, 6исходные после облучения Хе; 7 - после отжига $900^{\circ} \mathrm{C}, 45$ мин и облучения Хе; 8 - после отжига $900^{\circ} \mathrm{C}, 30$ мин и облучения Хе.

После проведения термообработок сигнал от кристаллической фазы InAs регистрируется для и для $\mathrm{SiO}_{2}(40 \mathrm{Hм}) / \mathrm{Si}$, и для $\mathrm{SiO}_{2}(0.6$ мКм $) / \mathrm{Si}$. Увеличение интенсивности сигнала после отжига может быть связано с ростом доли кристаллических кластеров InAs, с увеличением их размеров, а также с восстановлением структуры окружающей матрицы при термообработке. Стоит отметить, что в случае имплантации "кластерообразующих" ионов в оксид кремния положение максимума полосы ТО-фонона сдвинуто в более высокочастотную область, чем для имплантированного и отожженного образца $\mathrm{SiO}_{2}(40 \mathrm{HM}) / \mathrm{Si}$. Различие в положении максимумов может быть обусловлено тем, что размер нанокристаллов InAs больше в случае имплантации ионов As и In в $\mathrm{SiO}_{2}$, чем в $\mathrm{Si}$. Однако, по данным ПЭМ, размер нанокристалов InAs меньше в случае имплантации в оксид кремния, как до, так и после термообработок. Известно, что сдвиг в высокочастотную область полос TO- и LO-фононов InAs может быть связан с механическими напряжениями [10]. Следовательно, можно предположить, что сдвиг в высокочастотную область в нашем случае связан с наличием механических напряжений сжатия для нанокристаллов InAs, находящихся в матрице оксида кремния.

После облучения ионами ксенона сигнал от нанокристаллов InAs исчезает для всех исследованных образцов (не показано). Это может свидетельствовать об аморфизации нанокристаллов под действием облучения быстрыми ионами. Однако, по данным высокоразрешающей ПЭМ, большая часть кластеров InAs после облучения Хе остается в кристаллическом состоянии. Возможно, исчезновение сигнала КРС от нанокристаллов InAs обусловлено формированием радиационных дефектов в $\mathrm{Si}$ и $\mathrm{SiO}_{2}$ после облучения ионами Хе. Очевидно, что структурные изменения, происходящие в имплантированном слое, будут влиять на сигнал от кремниевой подложки.

Для всех исследуемых образцов облучение ионами Хе приводит к резкому уменьшению интенсивности полосы при $520 \mathrm{~cm}^{-1}$, связанной с рассеянием от кристаллического кремния. В случае имплантированного образца $\mathrm{SiO}_{2}(40 \mathrm{Hм}) / \mathrm{Si}$, резкое уменьшение интенсивности данной полосы указывает на формирование значительного количества радиационных дефектов в кремнии под слоем $\mathrm{SiO}_{2}$. В случае имплантированного образца $\mathrm{SiO}_{2}(0.6$ мкм $) / \mathrm{Si}$ полоса при $520 \mathrm{~cm}^{-1}$ связана с рассеянием от кремниевой подложки. Уменьшение интенсивности при $520 \mathrm{~cm}^{-1}$, вызванное облучением ионами Хе, вероятно, также связано с формированием радиационных дефектов в кремниевой подложке, поскольку пробег быстрых ионов ксенона составляет десятки микрон. Кроме того, в слое оксида кремния также могут формироваться радиационные дефекты, приводящие к уменьшению пропускания слоя $\mathrm{SiO}_{2}$ и соответственно к уменьшению сигнала от подложки. 


\section{ЗАКЛЮЧЕНИЕ}

Показано, что облучение быстрыми ионами Хе (167 МэВ, $3 \cdot 10^{14} \mathrm{~cm}^{-2}$ ) структуры $\mathrm{SiO}_{2}(0.6 \mathrm{MKм}) / \mathrm{Si}$ с нанокластерами InAs в оксидном слое приводит к упорядочению нанокластеров вдоль направления ионного пучка, причем форма более крупных преципитатов трансформируется от сферической к овальной с большой осью перпендикулярно поверхности образцов. Размер нанокластеров не превышает диаметр расплавленной области $\mathrm{SiO}_{2}$ вокруг траекторий ионов Хе, рассчитанной в рамках модели термического пика. По данным КРС, облучение ионами Хе приводит к аморфизации части нанокластеров InAs и введению большого количества дефектов в кристаллических кластерах.

\section{СПИСОК ЛИТЕРАТУРЫ}

1. Komarov F., Vlasukova L., Milchanin O. et al. // Nucl. Instrum. Methods. B. 2008. V. 266. P.3557.
2. Комаров Ф.Ф., Мильчанин О.В., Власукова Л.А. и др. // Изв. РАН. Сер. физ. 2010. Т. 74. № 2. С. 323; Bull. Russ. Acad. Sci. Phys. 2010. V. 74. № 2. P. 252.

3. Komarov F., Vlasukova L., Milchanin O. et al. // Mater. Sci. and Eng. B. 2013. V. 178. P. 1169.

4. Pruchnal S., Facsko S., Baumgart C. et al. // Nano Lett. 2011. V. 11. P. 2814.

5. Leino A.A., Djurabekova F., Nordlund K. // Eur. Phys. J. 2014. V. B. 87. P. 242.

6. Власукова Л.А., Комаров Ф.Ф., Ювченко В.Н. и др. // Изв. РАН. Сер. физ. 2012. Т. 76. № 5. С. 653; Bull. Russ. Acad. Sci. Phys. 2012. V. 76. № 5. P. 582.

7. Schmidt B., Heinig K.-H., Mücklich A. et al. // Nucl. Instrum. and Methods. 2009. V. B. 267. P. 1345.

8. Комаров Ф.Ф. // УФН. 2003. Т. 173. № 12. С. 1287; Phys. Uspekhi. 2003. V. 46. № 12. P. 1253.

9. Landölt-Börnstein J. // Numerical data and functional relationships in science and technology. BerlinHeidelberg: Springer-Verlag, 1982. P. 272.

10. Tenne D.A., Milekhin A.G., Bakarov A.K. et al. // Mat. Res. Soc. Symp. Proc. 2003. V. 737. P. E13.8.1. 